Article

\title{
Linking Female College Students' Causal Attribution Habits, Cultural Orientation, and Self-Efficacy: A Study on Cross-National Differences
}

\author{
Kerstin Hamann $^{1, *(\mathbb{D})}$, Ronan L. H. Wilson ${ }^{2} \mathbb{D}$, Bruce M. Wilson ${ }^{1}\left(\mathbb{D}\right.$ and Maura A. E. Pilotti ${ }^{3}$ (D) \\ 1 School of Politics, Security, and International Affairs, University of Central Florida, Orlando, FL 32816, USA; \\ Bruce.Wilson@ucf.edu \\ 2 Department of Psychology, University of South Florida, Tampa, FL 33620, USA; ronanwilson@usf.edu \\ 3 College of Sciences and Human Studies, Prince Mohammad Bin Fahd University, Al Khobar 31952, Saudi Arabia; \\ maura.pilotti@gmail.com \\ * Correspondence: Kerstin.Hamann@ucf.edu; Tel.: +407-823-2608
}

Citation: Hamann, K.; Wilson, R.L.H.; Wilson, B.M.; Pilotti, M.A.E. Linking Female College Students' Causal Attribution Habits, Cultural Orientation, and Self-Efficacy: A Study on Cross-National Differences. Sustainability 2022, 14, 1561.

https://doi.org/10.3390/su14031561

Academic Editors: Antonio-Manuel Rodríguez-García, María-Natalia Campos-Soto and Juan Carlos de la Cruz-Campos

Received: 4 January 2022

Accepted: 26 January 2022

Published: 28 January 2022

Publisher's Note: MDPI stays neutral with regard to jurisdictional claims in published maps and institutional affiliations.

Copyright: (C) 2022 by the authors. Licensee MDPI, Basel, Switzerland. This article is an open access article distributed under the terms and conditions of the Creative Commons Attribution (CC BY) license (https:// creativecommons.org/licenses/by/ $4.0 /)$.

\begin{abstract}
The present research concerns the extent to which explanations for desirable or undesirable academic outcomes (grades) as well as cultural orientation could account for self-efficacy beliefs of female undergraduate students from two societies with dissimilar cultural traditions. The United States of America (U.S.) was selected for its individualistic culture, whereas the Kingdom of Saudi Arabia (KSA) was chosen for its mix of traditional collectivist and individualistic values. A matchedpairs design ensured that students' self-efficacy levels were equated between cultural groups ( $\mathrm{n}=560$; 280 matched pairs). The research uncovered cultural differences in the choice of explanations and in the extent to which explanations might contribute to self-efficacy beliefs. These findings represent a blueprint for informing instructional interventions intended to effectively prepare students from different cultures for academic success.
\end{abstract}

Keywords: cultural orientation; self-efficacy; causal attribution habits; women; gender; cross-national differences; diversity

\section{Introduction}

The United Nations' Sustainable Development Goals (SDGs) list "inclusive and equitable quality education" as part of Goal \#4, Education. Targets and indicators include the elimination of gender disparities in education (Target 4.5), "global citizenship and appreciation of cultural diversity" (Target 4.7), and effective learning environments (Target 4.a) [1]. To accomplish this goal, it is paramount to further our understanding of the role of cultural differences in college students' learning experiences. The present study contributes to this understanding by analyzing the extent to which, and how, explanations for good and poor academic outcomes and cultural orientation account for the self-efficacy beliefs of female undergraduate students from two societies with dissimilar cultural traditions, the United States of American and the Kingdom of Saudi Arabia (KSA). The study employs a matched-pairs design to control for students' self-efficacy levels between cultural groups ( $n=560 ; 280$ matched pairs). Its findings are important for guiding pedagogical approaches that can effectively prepare students from varied cultural backgrounds for a successful college experience.

General self-efficacy is a psychological attribute that indicates confidence in one's abilities to meet challenges and find solutions to problems [2-5]. It is thought to be a motivational trait that is built on the cumulative successes and failures experienced by a person across a variety of circumstances over the lifespan [6,7]. Self-efficacy is considered to influence the initiation of actions, as well as the persistence with which people exercise such actions when they face difficulties and challenges. It is also presumed to facilitate a 
person's ability to adapt to new challenges and circumstances, thereby helping the person to overcome difficulties and increasing resilience to stress $[2,8,9]$. In line with these findings, self-efficacy is often reported to be positively correlated with college performance, though the strength of this relationship varies [10-12], and mixed results exist, illustrating either a negative relationship (reflecting the impact of over-confidence) or a null one [13-15].

Self-efficacy is a universal construct that generalizes across different cultures despite the existence of group differences. To illustrate, one study reported that persons belonging to individualistic cultures (e.g., western countries) have higher self-efficacy than those belonging to collectivist cultures (e.g., Far East countries) [16]. However, Luszczynska et al. [17] found variation in the general self-efficacy of participants from cultures that differ in their individualistic and collectivistic values according to Hofstede's scale [18] (United States, Germany, Poland, Turkey, and Costa Rica), but not alongside cultural values. Similarly, Crandall et al. [19] claimed that the general self-efficacy of young Qatari women, whose cultural values are assumed to be predominantly collectivistic, was comparable to that measured by Scholz et al. [16] in countries that vary in their emphasis on individualistic versus collectivistic values. $\mathrm{Wu}$ [20], in contrast, found no relationship between the individualism/collectivism dimension and self-efficacy estimates.

Some studies have linked self-efficacy beliefs to particular causal attribution preferences, especially in explanations of unpleasant outcomes (e.g., poor grades) [13,21] Explanations may rely on internal or external (i.e., situational) causes, each varying in the degree to which they reflect the power of personal agency (i.e., they are seen as controllable) [22]. Internal causes refer to attributes of a person, such as enduring dispositions (e.g., abilities and personality traits) or variable states (e.g., exerted effort). Situational causes refer to the context in which behavior is displayed, such as task difficulty, instructors' biases, luck, and help from family or friends. Each of these causes may be perceived as more or less beyond the agent's control (e.g., effort versus luck). Causal attributions linked to varying degrees of self-efficacy are pertinent and consequential to students' success in college $[23,24]$. Students with low self-efficacy may react defensively when things go wrong, blaming others or the particular circumstances they faced (external causes). Alternatively, such students may interpret unpleasant outcomes as evidence of their incompetence (internal cause). Either rejecting personal responsibility for poor performance or attributing it to incompetence entails a cause that, at the moment the events are faced, is perceived as being largely beyond the students' reach, thereby depriving such students of the opportunity to consider remedial actions to improve future performance. Not surprisingly, students beliefs in their ability to exert control over events in their lives (internal locus of control) are positively related to good performance (as measured by grades). In contrast, beliefs that events are influenced by forces beyond their reach (external locus of control) result in poor performance $[25,26]$.

Interestingly, the way in which individuals habitually explain actions and outcomes (i.e., causal attribution habits) [27] varies across cultures. Westerners tend to explain events by attributing responsibility to individuals seen as causal agents whose conduct is largely detached from the context in which they exist. That is, westerners exhibit a preference for internal attributions [28]. As a result, when describing themselves or other individuals, they refer to general as well as abstract personality traits [29]. Easterners, instead, tend to see themselves and others as responsive to the context in which they exist, thereby exhibiting a preference for external attributions. Their contextualized view of human agency leads them to rely on social identities as main descriptors of themselves and others [29]. Crosscultural evidence of students in the West and the Far East illustrates that preferences for either internal or external attributions tend to adjust to the desirability of the events to be explained [30-33]. In western societies, students tend to take credit for success and attribute failure to external circumstances. Thus, they appear to display a self-serving bias that nurtures self-enhancement and self-defensive needs. In the Far East, students tend to display a self-critical bias, preferring to attribute success to external causes and failure to internal ones. In the studies reviewed above, though, it is not clear whether causal 
attribution habits for desirable or undesirable outcomes differ [34] if self-efficacy is equated between cultural groups. That is, at comparable levels of self-efficacy, do students' beliefs that their academic successes or failures are due to internal (ability or effort) or external (luck, instructors, or friends) circumstances still vary along cultural orientation lines?

Pedagogical research has focused on cultural differences across countries or even broader geographical areas, treating countries or areas as isomorphic to a unique set of cultural traits. Our research puts forward a novel approach that is based on collecting individual-level data on cultural orientation to provide a comparison of two diverse cultures. As such, it differs from the more traditional approach of equating the assumed aggregated cultural values of a geographical area to those of single individuals living in that area (see [3]). It also includes an underrepresented population (i.e., female college students attending a university in the Kingdom of Saudi Arabia) for comparison.

Our cross-cultural study involves a comparison of two groups of female undergraduate students for whom self-efficacy beliefs have been equated. Students are either from the USA or the Kingdom of Saudi Arabia (KSA). The USA can be described as a western country, with a predominantly individualistic culture. It differs from the predominant culture of KSA with its emphasis on collectivist values intermixedwith the recognition of the role of the individual $[35,36]$. KSA is a traditionally conservative country guided by patriarchal and tribal valuesthat foster a hierarchical social structure in which gender and tribal affiliation determine one's place in the society, as well as by the collectivist principles of Islam, which promote egalitarianism $[36,37]$. These apparent contradictions coexist undisturbed in the everyday life of its citizens, along with notable western influences that are largely endorsed by younger citizens whose bilingualism and biculturalism reflect their growing exposure modernization and foreign language education (e.g., English or French) [38]. One of these influences, of more recent import, is the institutional promotion of gender equity in educational attainment and the workforce, which places female students at the forefront of economic diversification efforts intended to move the country away from its almost exclusive reliance on oil resources [39]. Thus, KSA female undergraduate students are specifically selected for comparison with U.S. female undergraduate students because it is unclear how they are adjusting to their new status and where they fall on the cultural spectrum between eastern and western cultures.

The research is guided by a set of key questions regarding (a) group differences, $(b, c)$ the contribution of casual attribution preferences and cultural orientation to self-efficacy, and (d) the relevance of self-efficacy to each cultural group's academic performance:

a. If self-efficacy is equated between the two groups by pairing each U.S. student with a KSA student, are there group differences in causal attribution preferences? Is the cultural orientation of these two groups different as suggested by the extant literature?

b. How do explanations for best and worst outcomes account for self-efficacy in each group?

c. How is cultural orientation related to self-efficacy in each group?

d. Is self-efficacy in both groups related to academic performance (as indexed by class grades)?

\section{Materials and Methods}

\subsection{The Sample}

The study's participants were 560 female undergraduate students organized into two groups by country of college enrollment: 280 students who took a core course (American Government) at a U.S. university, and 280 students who took a core course (Arabic Studies) at a university in KSA. While different in the material covered, the selected core courses are largely equivalent if they are thought of as offering an overview of the norms, rules, and principles upon which each society rests, and as fulfilling a similar function in the selected universities' curricula. Namely, undergraduate students from across all majors at each university take these foundational core courses. Thus, courses were specifically chosen to obtain a sufficiently representative sample of the students at each university.

Participation was voluntary (convenience sample). Students were between 18 and 25 years old. The subject pool of volunteers from which selections were made included 
1265 students. Each volunteer was given a randomly generated code that was displayed in datasheets to ensure confidentiality. General self-efficacy ratings provided the bases for matching each U.S. student with a KSA student, which resulted in 280 pairs of participants. Two basic rules were adopted to create pairs. In the absence of a perfect match, the closest match was chosen. In contrast, if multiple participants matched, pairing was determined by random selection. Participant treatment complied with the standards of the Office for Human Research Protections of the U.S. Department of Health and Human Services and with the code of ethics of the American Psychological Association. The study was approved by the Institutional Review Board and Deanship of Research of the respective universities.

All KSA participants were of Middle Eastern descent (all were Saudi citizens born in Saudi Arabia) and the sample was ethnically homogenous. Participants in the U.S. included students from diverse ethnic and racial backgrounds: White: $43.9 \%$; Hispanic: 26.8\%, Black: 11.8\%, Asian: 5.0\%, and mixed or unclassified: 12.5\%. Ethnic composition reflected cross-national differences in university enrollment, thereby ensuring the study's ecological validity.

\subsection{Materials and Procedure}

At the start of each course, participants volunteered to complete three questionnaires: the New General Self-Efficacy (NGSE) scale of Chen et al. [40] questionnaire, the causal attribution questionnaire of McClure et al. [41], and the cultural orientation questionnaire of Triandis and Gelfland [42]. To foster candid responses, students were promised confidentiality.

The NGSE $[40,43]$ scale consisted of eight statements intended to measure students' confidence regarding their abilities across several life circumstances. Each statement of the questionnaire was followed by a 5-point Likert scale from 'strongly disagree' to 'strongly agree'. Students indicated the extent of their agreement with each of the statements. Cronbach's alpha (i.e., a reliability coefficient that measures the internal consistency of an assessment tool) was 0.84 .

The causal attribution questionnaire of McClure et al. [41] was intended to gauge how students explained their highest and lowest grades. The questionnaire first required students to recall the experience of receiving their best as well as their worst grade on an academic assessment. They then had to estimate how much each of the seven causes contributed to either grade on a scale from 0 (not at all) to 6 (entirely). The contemplated causes were ability, effort, test (either difficulty or ease), luck, family, instructor, and friends. Cronbach's alpha was 0.60. According to pilot work involving focus groups of undergraduate students, agreement existed that ability and effort were internal causes, whereas test, luck, family, and friends were external causes. Causes differed in the degree to which they were perceived to be under students' control, including from largely controllable (i.e., effort) to beyond one's reach (i.e., luck).

The cultural orientation questionnaire of Triandis and Gelfland [42] assessed students' orientation regarding beliefs that define their culture. The four possible orientations are vertical collectivism (VC; which describes seeing oneself as a member of a hierarchically organized community who accepts its inequalities), vertical individualism (VI; which refers to seeing oneself as an independent being who accepts the inequalities of the community in which one lives), horizontal collectivism (HC; which means seeing oneself as part of a community of equals among equals), and horizontal individualism (HI; which refers to seeing oneself as an independent being in a community of equals among equals). Participants assessed the extent to which these four categories of cultural beliefs about oneself applied to them on a 9-point Likert scale ranging from 0 (never) to 8 (always), with 4 presenting the neutral point. Cronbach's alpha was 0.80 .

\section{Results}

All results of inferential statistics discussed in this study were considered significant at the 0.05 level. If analysis of variance (ANOVA) was employed, significant effects were 
followed by tests of simple effects. The Bonferroni inequality formula was then applied to adjust for familywise alpha.

\subsection{Are There Group Differences?}

Table 1 presents the descriptive statistics (mean, $M$, and standard error of the mean, $S E M$ ) of the key variables of the study, organized by cultural group: self-efficacy, causal attribution preferences for desirable and undesirable outcomes, and cultural orientation. In the table, SEM is reported (instead of the standard deviation, SD) to provide a measure of the extent to which individual sample means estimate the mean of the population to which they belong (i.e., SD divided by the square root of the sample size).

Table 1. Descriptive Statistics.

\begin{tabular}{|c|c|c|c|c|c|}
\hline Variable & $\begin{array}{c}\text { USA } \\
\text { Mean }\end{array}$ & $S E M$ & $\begin{array}{c}\text { KSA } \\
\text { Mean }\end{array}$ & SEM & Sign. \\
\hline $\begin{array}{c}\text { Self-Efficacy } \\
\text { Best Grade }\end{array}$ & \multicolumn{5}{|c|}{ Best Grade } \\
\hline Abilities & 4.80 & 0.067 & 4.03 & 0.069 & $<0.001$ \\
\hline Effort & 5.11 & 0.067 & 4.81 & 0.074 & 0.003 \\
\hline Test & 3.06 & 0.084 & 3.32 & 0.098 & ns \\
\hline Luck & 1.88 & 0.096 & 2.27 & 0.110 & $n s$ \\
\hline Family & 1.52 & 0.102 & 2.69 & 0.123 & $<0.001$ \\
\hline Instructor & 3.78 & 0.084 & 4.16 & 0.092 & 0.003 \\
\hline Friends & 1.45 & 0.101 & 2.25 & 0.115 & $<0.001$ \\
\hline \multicolumn{6}{|l|}{ Worst Grade } \\
\hline Abilities & 3.02 & 0.099 & 2.49 & 0.099 & $<0.001$ \\
\hline Effort & 4.21 & 0.097 & 2.97 & 0.110 & $<0.001$ \\
\hline Test & 4.37 & 0.075 & 4.34 & 0.097 & ns \\
\hline Luck & 1.55 & 0.094 & 2.14 & 0.114 & $<0.001$ \\
\hline Family & 0.73 & 0.074 & 2.00 & 0.126 & $<0.001$ \\
\hline Instructor & 2.93 & 0.099 & 3.65 & 0.112 & $<0.001$ \\
\hline Friends & 1.01 & 0.082 & 1.06 & 0.092 & $n s$ \\
\hline \multicolumn{6}{|c|}{ Cultural Orientation } \\
\hline $\mathrm{HI}$ & 6.24 & 0.069 & 6.4 & 0.068 & $n s$ \\
\hline VI & 4.02 & 0.083 & 4.44 & 0.096 & 0.001 \\
\hline $\mathrm{HC}$ & 5.79 & 0.074 & 6.24 & 0.082 & $<0.001$ \\
\hline $\mathrm{VC}$ & 5.43 & 0.080 & 6.49 & 0.086 & $<0.001$ \\
\hline
\end{tabular}

Note. Significant differences between U.S. and KSA students are displayed in the last column.

As expected, ANOVA showed that participants' self-efficacy was not significantly different between cultural groups, $F<1.00$, ns. Thus, participants were judged to have been effectively matched on self-efficacy. Of course, it was of interest to assess whether cultural groups were indeed different in cultural beliefs regarding the self and others. A 2 (cultural group) X 4 (cultural orientation) mixed factorial ANOVA conducted on ratings for cultural preferences displayed a main effect of cultural orientation, $F(3,1674)=401.58, M S E=1.25$, $p<0.001, \eta p^{2}=0.418$, a main effect of cultural group, $F(1,558)=44.08, M S E=3.46, p<0.001$, $\eta p^{2}=0.073$, and a significant interaction, $F(3,1674)=16.55, M S E=1.25, p<0.001, \eta p^{2}=0.029$. Tests of simple effects (Bonferroni alpha: 0.001) suggested that U.S. and KSA students did not differ in $\mathrm{HI}$, whereas students from KSA were more likely to select $\mathrm{HC}$, VI, and VC than their U.S. counterparts. However, if ratings were ranked based on the magnitude of the preference expressed by each group, the first two choices of U.S. students were HI and $\mathrm{HC}$, reflecting a preference for considering oneself and others equals among equals. KSA students' first two choices were VC and HI, reflecting a recognition of the conflicting values of a society organized hierarchically along tribal and gender lines, driven by the equalitarian and collectivistic credo of the religion of Islam, and influenced by the notion of self-reliance and independence mostly of western import.

A 2 (cultural group) X 7 (cause) mixed factorial ANOVA, conducted on the ratings for best grades, displayed a main effect of cause, $F(6,3348)=427.43, M S E=2.06, p<0.001$, 
$\eta p^{2}=0.434$, and a main effect of cultural group, $F(1,558)=16.02, M S E=4.66, p<0.001$, $\eta p^{2}=0.028$. There was also a significant interaction, $F(6,3348)=28.56, M S E=2.06$, $p<0.001, \eta p^{2}=0.049$. Tests of simple effects indicated that cultural groups differed in their explanations (Bonferroni alpha: 0.007). Specifically, U.S. students were more likely to explain desirable outcomes by relying on personal abilities and effort (i.e., internal causes) compared to KSA students, who in turn preferentially chose family, friends, and instructors (i.e., external causes).

The same ANOVA performed on worst grades produced a main effect of cause, $F(6,3348)=350.19, M S E=2.43, p<0.001, \eta p^{2}=0.386$, a main effect of cultural group, $F(1,558)=3.05, M S E=4.54, p=0.005, \eta p^{2}=0.005$, and a significant interaction, $F(6,3348)=40.40$, $M S E=2.43, p<0.001, \eta p^{2}=0.068$. Tests of simple effects (Bonferroni alpha: 0.007) were conducted to understand the nature of cultural groups' differences. As for desirable outcomes, U.S. students preferred to account for undesirable grades by relying on abilities and effort (internal causes) whereas KSA students privileged luck, family, and instructors (external causes).

In sum, differences between cultural groups emerged in the way students explained academic outcomes. Although U.S. students relied on similar explanations for desirable and undesirable outcomes by evoking internal causes, KSA students slightly differentiated between outcomes. In contrast to their U.S. counterparts, they relied on external causes to explain both desirable and undesirable outcomes, thereby deflecting responsibility for what might be judged as unpleasant. KSA students also opted for similar explanations for desirable as well as undesirable outcomes; however, there was one exception: They attributed desirable academic occurrences to friends, but they called upon luck to account for undesirable occurrences, suggesting that the desire to preserve the cohesiveness of their social networks required deflecting the responsibility for unpleasant occurrences to depersonalized events beyond anybody's control.

When explanations were ranked based on the magnitude of the preference expressed in each group, U.S. participants favored effort and ability regarding good grades, while holding test difficulty and effort responsible for bad grades. Thus, participants from the U.S. distinguished between desirable and undesirable outcomes, choosing internal causes for pleasant results, but a mixture of internal and external causes for unpleasant ones. Although attributing a bad grade to test difficulty might alleviate personal responsibility for the unpleasant outcome, attributing the grade to effort is a recognition that not only personal responsibility exists but also the outcome is a rectifiable event by the agent.

KSA students, on the other hand, preferentially chose a mixture of internal and external causes for desirable outcomes (effort and instructors) and they preferentially attributed undesirable outcomes to external causes (instructors and test difficulty). Thus, for these students, explanations of relevant outcomes were more likely to locate agency outside of themselves than U.S. students.

\subsection{Do Explanations for Best and Worst Grades Account for Self-Efficacy?}

Regression analyses were carried out for U.S. and KSA students separately to determine whether explanations for either best or worst grades, serving as the predictor variables, contributed differently to self-efficacy, serving as the outcome variable. Tables 2 and 3 display the results of these analyses.

There were differences in how explanations contributed to the self-efficacy beliefs of the participants depending on the country of origin. When U.S. participants explained good grades as due to exerted effort (an internal cause modifiable by the agent), the attribution benefited self-efficacy beliefs, whereas the attribution of such outcomes to luck (an external cause that is beyond the reach of the agent) harmed self-efficacy beliefs. In comparison, when KSA participants explained good grades as due to their abilities (an internal cause that was perceived as hard to modify), self-efficacy beliefs benefited, whereas the attribution of such outcomes to test difficulty (an internal cause that is beyond the control of the agent) harmed self-efficacy beliefs. 
Table 2. Regression analyses for "Best Grade" with causal attribution ratings as the predictor variables, and self-efficacy as the outcome variable.

\begin{tabular}{cccccc}
\hline & $\boldsymbol{B}$ & SE & Beta & $\boldsymbol{t}$ & Sig. \\
\hline Best Grade-USA & & & & & \\
Constant & 2.283 & 0.192 & & 1.790 & $n s$ \\
Abilities & 0.049 & 0.027 & 0.107 & 3.198 & 0.002 \\
Effort & 0.088 & 0.027 & 0.194 & -0.489 & $n s$ \\
Test & -0.011 & 0.023 & -0.030 & -2.077 & 0.039 \\
Luck & -0.044 & 0.021 & -0.138 & -0.049 & $n s$ \\
Family & -0.001 & 0.018 & -0.003 & 10.745 & $n s$ \\
Instructor & 0.039 & 0.022 & 0.107 & 10.113 & $n s$ \\
Friends & 0.022 & 0.020 & 0.073 & & \\
Best Grade-KSA & & & & \\
Constant & 2.302 & 0.144 & & 5.722 & 0.000 \\
Abilities & 0.155 & 0.027 & 0.352 & 1.273 & $n s$ \\
Effort & 0.033 & 0.026 & 0.080 & -2.389 & 0.018 \\
Test & -0.047 & 0.020 & -0.150 & -1.282 & $n s$ \\
Luck & -0.022 & 0.017 & -0.081 & 1.747 & $n s$ \\
Family & 0.026 & 0.015 & 0.104 & 1.172 & $n s$ \\
Instructor & 0.024 & 0.020 & 0.071 & -0.652 & \\
Friends & -0.011 & 0.017 & -0.041 & &
\end{tabular}

Note. USA: $R=0.343$. KSA: $R=0.437$.

Table 3. Regression analyses for "Worst Grade" with causal attribution ratings as the predictor variables, and self-efficacy as the outcome variable.

\begin{tabular}{|c|c|c|c|c|c|}
\hline & $B$ & $S E$ & Beta & $t$ & Sig. \\
\hline \multicolumn{6}{|c|}{ Worst Grade-USA } \\
\hline Constant & 3.181 & 0.155 & & & \\
\hline Abilities & -0.031 & 0.018 & -0.099 & -10.656 & ns \\
\hline Effort & 0.003 & 0.019 & 0.009 & 0.150 & ns \\
\hline Test & 0.024 & 0.026 & 0.059 & 0.926 & ns \\
\hline Luck & -0.002 & 0.022 & -0.007 & -0.095 & ns \\
\hline Family & -0.044 & 0.028 & -0.106 & -10.562 & $n s$ \\
\hline Instructor & -0.039 & 0.020 & -0.128 & -10.976 & 0.049 \\
\hline Friends & -0.029 & 0.026 & -0.079 & -10.129 & ns \\
\hline \multicolumn{6}{|c|}{ Worst Grade-KSA } \\
\hline Constant & 3.212 & 0.111 & & & \\
\hline Abilities & -0.042 & 0.019 & -0.137 & -2.224 & 0.027 \\
\hline Effort & -0.013 & 0.017 & -0.048 & -0.770 & ns \\
\hline Test & 0.022 & 0.021 & 0.070 & 10.065 & ns \\
\hline Luck & -0.056 & 0.017 & -0.209 & -3.273 & 0.001 \\
\hline Family & 0.019 & 0.015 & 0.076 & 1.214 & ns \\
\hline Instructor & -0.016 & 0.018 & -0.058 & -0.884 & ns \\
\hline Friends & 0.004 & 0.021 & 0.011 & 0.170 & ns \\
\hline
\end{tabular}

Note. USA: $R=0.246$. KSA: $R=0.247$.

Overall, explanations for undesirable outcomes tended to be negatively related to self-efficacy beliefs; however, the results suggested dissimilarities between U.S. and KSA students. For U.S. students, the attribution of undesirable outcomes to instructors (an external cause) hurt self-efficacy beliefs. For KSA students, ascribing such results to abilities (an internal cause that was perceived as hard to modify) and luck (an external cause beyond the agent's control) hurt self-efficacy beliefs. The latter causes suggest that for KSA students, the less agency they assumed when faced with unpleasant events, the lower were their self-efficacy beliefs. 


\subsection{Is Cultural Orientation Related to Self-Efficacy?}

Separate regression analyses for participants from each country were conducted with self-efficacy as the outcome variable and cultural dimensions (HI, VI, HC, and VC) as the predictor variables. The results of these regressions are displayed in Table 4.

Table 4. Regression analyses with cultural dimensions as the predictors, and self-efficacy as the dependent variable.

\begin{tabular}{cccccc}
\hline Country & $\boldsymbol{B}$ & $\boldsymbol{S E}$ & Beta & $\boldsymbol{t}$ & Sig. \\
\hline USA & & & & & \\
Constant & 1.343 & 0.188 & & & \\
HI & 0.177 & 0.025 & 0.400 & 6.945 & 0.000 \\
VI & 0.018 & 0.019 & 0.049 & 0.924 & $n s$ \\
HC & 0.036 & 0.023 & 0.089 & 1.571 & $n s$ \\
VC & 0.054 & 0.023 & 0.143 & 2.308 & 0.022 \\
KSA & & & & & \\
Constant & 1.877 & 0.187 & & & \\
HI & 0.127 & 0.028 & 0.281 & 4.462 & 0.000 \\
VI & 0.027 & 0.020 & 0.084 & 1.346 & $n s$ \\
HC & 0.058 & 0.027 & 0.158 & 2.165 & 0.031 \\
VC & -0.023 & 0.027 & -0.064 & -0.841 & $n s$ \\
\hline
\end{tabular}

Note. USA: $R=0.514$. KSA: $R=0.372$.

For U.S. students, self-efficacy was supported by beliefs in HI and VC while for KSA students, it was supported by beliefs in HI and HC. Therefore, appreciating equality added to the confidence that KSA students perceived in their capacity to overcome challenges and difficulties, which was linked to the idea of the self as either independent or dependent on a collective of other beings. When U.S. students recognized a mixture of conflicting orientations, it contributed positively to their self-confidence in overcoming challenges and difficulties. Namely, appreciating equality contributed to their self-confidence, but only when embedded in an independent self. In contrast, an appreciation for inequalities supported their self-confidence, but only when exhibited by a self that is dependent on the collective to which it belongs.

\subsection{Is Self-Efficacy Related to Academic Performance?}

If self-efficacy is to be considered relevant to educational interventions targeting at-risk students, and, more broadly, to actions intended to improve curricula and instructional methods, its link to academic success is to be established first. In the present study, a Pearson correlation was conducted between final class grades and self-efficacy to determine the extent to which knowing students' self-efficacy could predict academic success, measured by final class grades in each cultural group. For U.S. students, whose average performance was $85.81 \%(S E M=0.555)$, self-efficacy beliefs did not predict performance, $r=0.08$, $n=280, n s$, two tails. In contrast, for KSA students, whose average final class performance was $81.12(S E M=0.915)$, self-efficacy increased with grades, $r=0.15, n=280, p=0.014$, two tails. Yet, although positive, the relationship between the two variables was weak, thereby indicating that the contribution to performance made by general self-efficacy was rather minor. The latter finding is not surprising since complex tasks with heavy cognitive demands, such as class activities in college courses, tend to generate weaker relationships between performance and self-efficacy $[14,15]$. In this context, the absence of a relationship between the two variables may be due to students' (mis)perceived ease of a course's curriculum, which may not activate self-efficacy beliefs during the semester, thereby reducing their impact on performance [13]. In support of this assumption, the class performance of U.S. students was overall higher than that of KSA students, and less variable, $F(3,558)=19.24, M S E=160.36, p<0.001, \eta p^{2}=0.033$. 


\section{Discussion and Conclusions}

The present study investigated whether explanations for desirable and undesirable outcomes as well as cultural orientation might account for the self-efficacy of U.S. and KSA students differently. A matched-pairs design was employed. Our results suggested differences in how causal attribution habits and cultural orientation might be related to the self-efficacy of students whose cultural background differs, even when such students have identical self-efficacy scores and gender is held constant (only female participants were included).

These results are meaningful to instructors, advisors, and other university personnel who are concerned that to foster academic success, the needs of students from different cultural backgrounds are to be understood and addressed. At its core, the claim of relevance relies on evidence that general self-efficacy plays a role in academic success. To wit, if self-efficacy is conceptualized as a motivational trait [42] linked to learners' engagement/motivation [43,44], it is expected to translate into actions (e.g., completion rates, dedication, commitment, goal-setting, etc.) conducive to academic accomplishments in specific tasks as well as overall [45-52]. However, evidence also exists either of an inverse relationship between self-efficacy and educational success (when self-efficacy becomes over-confidence) or of no relationship at all [53-55]. In our research, self-efficacy predicted academic success (as measured by class grades) only for KSA students, suggesting that information about self-efficacy may be differentially useful depending on the context in which it is gathered.

Overall, we believe our study can serve as a blueprint for educators and administrators who aim to improve the educational experiences of students from different cultural backgrounds, including remedial interventions. Yet, first and foremost, it is necessary to identify the role self-efficacy plays in predicting academic performance (either in particular courses or overall through GPA) for a given student population. To this end, academic records available to faculty and administrators may provide useful data. If evidence is found of a positive relationship, as per KSA students, recognition of the sources upon which self-efficacy beliefs develop is required for intervention. As noted by Bandura [2], self-efficacy results from four main distinct sources: mastery experience, vicarious experience, verbal persuasion, and physiological state. Mastery experience is achieved when learners are successful in their endeavors, thereby supporting the conviction that they possess the attributes to accomplish a task or a variety of tasks. Vicarious experience refers to role-modeling that provides learners with operational frameworks to accomplish certain tasks, thereby enhancing their belief that they can replicate the success. Verbal persuasion results from the positive feedback received from trusted and respected individuals. Lastly, the physiological states of learners, such as anxiety, stress, fatigue, and mood, are recognized as capable of informing self-efficacy beliefs. Namely, learners interpret their physiological states of arousal as indicators of competence or lack thereof. Usher and Pajares [50] add explanatory or attributional style as another factor capable of shaping self-efficacy by affecting the way learners interpret the causes of their successes and failures or those of others. Any of these sources, though, is likely to enhance self-efficacy when it underscores how success results from devoting adequate effort to mastering acquirable competencies instead of depending upon natural talents [13].

An educational intervention intended to improve students' performance in a given course may then target any of these sources [13]. For instance, if mastery experience is targeted, a series of interconnected active learning activities accompanied by coaching may be added to a course's instructional method. Prior to implementation, pedagogical training can be offered to faculty to ensure successful execution. If vicarious experience is the target, demonstrations and mentoring opportunities can be added to course activities. Faculty can also be trained to offer feedback emphasizing that required competencies are acquirable and that academic success in the course results from working towards mastering such skills. Students' interpretations of physiological states experienced in particular activities or across the entire course may also be targeted through counseling outside the classroom. Most 
importantly, workshops and counseling sessions devoted to the impact of attributional styles on learners' preparatory and in-class behaviors, and their purported short-term and long-term consequences, may also induce self-reflection capable of motivating change.

If there is no evidence that a relationship exists between the two variables in a particular group of students (e.g., U.S. student), but exists in a comparable group (e.g., KSA students), one possible reason may be the (mis)perceived ease of a course, which may not activate self-efficacy beliefs during the semester, thereby reducing their impact on performance [13]. Namely, it may be the case that some students expect core courses, which are lower-level introductory courses, to be less challenging than upper-level specialized courses in their major field of study. As a result, educators may want to review course activities, such as tests and assignments, materials covered, and modes of coverage, to develop more intellectually challenging courses, thereby dispelling expectations.

\section{Limitations of the Study}

The present study has limitations that future research should address. First, our reliance on female students was intended to emphasize cultural group differences specifically regarding the stereotypic beliefs about gender that students hold in societies that differ in their explicit emphasis on patriarchal values. Research with U.S. samples has reported self-efficacy beliefs to vary by gender [56]. Additional studies may explore further how the context of a masculine culture as that of KSA (see [18]) may condition male students' perception of self-efficacy. Namely, does the power given to one's gender in societies that vary in patriarchal values inflate self-efficacy to the point of inverting its relationship with performance? Second, in-depth qualitative analyses may be needed to understand the specific meaning of each of the causes listed in the McClure et al. [41] questionnaire [57]. In-house focus groups have underscored that the dimension internal versus external is uniformly understood by students as dichotomous, whereas the dimension controllability (i.e., whether a student's behavior can impact the course of an envisioned outcome [22]) tends to be perceived as a continuum. To wit, one's effort is consistently reported to be a controllable cause of performance, much more than ability, which is seen as more difficult and slower to change, whereas luck is perceived as beyond personal agency. Third, the ethnic diversity of the U.S. sample relative to the uniformity of the KSA sample was intended to offer ecological validity to the comparisons of cultural groups. Yet, it is reasonable to question whether changes to the ethnic composition of the U.S. sample might change the contribution of causal attribution and cultural orientation to self-efficacy. Thus, the issue of the extent to which such contribution in the U.S. sample is shaped by each ethnicity is of interest. A much larger sample of each ethnicity would be required for inferential statistics to be reliably informative regarding this issue. Notwithstanding the challenges of obtaining such samples, it remains a fruitful endeavor of future research. Fourth, the findings of our matched-pairs design illustrating the contribution of different explanations to self-efficacy are partially consistent with those of Silver et al. (1995), who reported that individuals with high self-efficacy are likely to explain desirable outcomes with internal causes, whereas undesirable outcomes are attributed to situational causes. For both U.S. and KSA students who were asked to explain a desirable outcome, we found that internal causes were positively related to self-efficacy, whereas external causes were inversely related to it. However, when students were asked to explain an undesirable outcome, our results differed from those of Silver et al. [58]. Namely, although for both U.S. and KSA students, external causes were inversely related to self-efficacy, for KSA students, an internal cause (i.e., ability) was also inversely related to self-efficacy. Furthermore, in contrast to our results, other studies $[59,60]$ did not report evidence of a relationship between self-efficacy and causal attribution preferences. The variability in the results obtained by different studies hints at the need to examine large samples across different institutions of higher education and localities.

Our methodology and findings bring to the forefront additional issues that underscore the necessity to better understand teaching and learning in higher education. Despite its 
limitations, the current research contributes to the existing research by presenting the easyto-use methodological blueprint of an evidence-based approach that educators at a variety of educational institutions can adopt to recognize how specific cognitive variables may define students' self-efficacy beliefs and their purported relationship with academic success.

Author Contributions: Conceptualization, K.H., R.L.H.W., B.M.W. and M.A.E.P.; methodology, K.H., R.L.H.W., B.M.W. and M.A.E.P.; validation, M.A.E.P.; formal analysis, M.A.E.P.; investigation, K.H., R.L.H.W., B.M.W. and M.A.E.P.; data curation, K.H., B.M.W. and M.A.E.P.; writing—original draft preparation, K.H., R.L.H.W., B.M.W. and M.A.E.P.; writing-review and editing, K.H., R.L.H.W., B.M.W. and M.A.E.P. All authors have read and agreed to the published version of the manuscript.

Funding: This research received no external funding.

Institutional Review Board Statement: This study was conducted according to the guidelines of the Declaration of Helsinki. It was approved by the Institutional Review Board of UCF (ID\#: STUDY00001215, approval date 9 January 2020), and by the Deanship of Research and Faculty Affairs of PMU.

Informed Consent Statement: Informed consent was obtained from the subjects involved in the study.

Data Availability Statement: Data will be made available upon request.

Acknowledgments: The authors would like to thank the instructors who made their classes available for data collection and the university personnel who provided demographic data for the students.

Conflicts of Interest: The authors declare no conflict of interest.

\section{References}

1. United Nations. Sustainable Development Goals. Available online: https://sdgs.un.org/goals (accessed on 3 January 2022).

2. Bandura, A. Self-efficacy: Toward a unifying theory of behavioral change. Psychol. Rev. 1977, 84, 191-215. [CrossRef] [PubMed]

3. Bartimote-Aufflick, K.; Bridgeman, A.; Walker, R.; Sharma, M.; Smith, L. The study, evaluation, and improvement of university student self-efficacy. Stud. High. Educ. 2016, 41, 1918-1942. [CrossRef]

4. Majer, J.M. Self-efficacy and academic success among ethnically diverse first-generation community college students. J. Divers. High. Educ. 2009, 2, 243-250. [CrossRef]

5. Roick, J.; Ringeisen, T. Self-efficacy, test anxiety, and academic success: A longitudinal validation. Int. J. Educ. Res. 2017, 83, 84-93. [CrossRef]

6. Gecas, V. The social psychology of self-efficacy. Annu. Rev. Sociol. 1989, 15, 291-316. [CrossRef]

7. Shelton, S.H. Developing the construct of general self-efficacy. Psychol. Rep. 1990, 66, 987-994. [CrossRef]

8. Pulakos, E.D.; Arad, S.; Donovan, M.A.; Plamondon, K.E. Adaptability in the workplace: Development of a taxonomy of adaptive performance. J. Appl. Psychol. 2000, 85, 612-624. [CrossRef]

9. Schueler, K.; Fritz, J.; Dorfschmidt, L.; Van Harmelen, A.L.; Stroemer, E.; Wessa, M. Psychological network analysis of general self-efficacy in high vs. low resilient functioning healthy adults. Front. Psychiat. 2021, 12, 736147. [CrossRef]

10. Bouih, A.; Nadif, B.; Benattabou, D. Assessing the effect of general self-efficacy on academic achievement using path analysis: A preliminary study. J. Eng. Teach. Learn. 2021, 3, 18-24. [CrossRef]

11. Byrne, M.; Flood, B.; Griffin, J. Measuring the academic self-efficacy of first-year accounting students. Account. Educ. 2014, 23, 407-423. [CrossRef]

12. Lane, J.; Lane, A.M.; Kyprianou, A. Self-efficacy, self-esteem and their impact on academic performance. Soc. Behav. Personal. 2004, 32, 247-256. [CrossRef]

13. Heslin, P.A.; Klehe, U.C. Self-efficacy. In Encyclopedia of Industrial/Organizational Psychology; Rogelberg, S.G., Ed.; Sage: Thousand Oaks, CA, USA, 2006; pp. 705-708.

14. Lane, J.; Lane, A.M. Self-efficacy and academic performance. Soc. Behav. Personal. 2001, 29, 687-694. [CrossRef]

15. Lent, R.W.; Hackett, G. Career self-efficacy: Empirical status and future directions. J. Vocat. Behav. 1987, 30, 347-382. [CrossRef]

16. Scholz, U.; Doña, B.G.; Sud, S.; Schwarzer, R. Is general self-efficacy a universal construct? Psychometric findings from 25 countries. Eur. J. Psychol. Assess. 2002, 18, 242-251. [CrossRef]

17. Luszczynska, A.; Gutiérrez-Doña, B.; Schwarzer, R. General self-efficacy in various domains of human functioning: Evidence from five countries. Int. J. Psychol. 2005, 40, 80-89. [CrossRef]

18. Hofstede, G.H. Culture's Consequences, 2nd ed.; Sage: Thousand Oaks, CA, USA, 2001.

19. Crandall, A.; Rahim, H.A.; Yount, K.M. Validation of the general self-efficacy scale among Qatari young women. East. Mediterr. Health J. 2015, 21, 891-896. [CrossRef]

20. Wu, C.-H. Factor analysis of the General Self-Efficacy Scale and its relationship with individualism/collectivism among twentyfive countries: Application of multilevel confirmatory factor analysis. Pers. Indiv. Differ. 2009, 46, 699-703. [CrossRef] 
21. Van Dinther, M.; Dochy, F.; Segers, M. Factors affecting students' self-efficacy in higher education. Educ. Res. Rev. 2011, 6, 95-108. [CrossRef]

22. Weiner, B. Intrapersonal and interpersonal theories of motivation from an attributional perspective. Educ. Psychol. Rev. 2000, 12, 1-14. [CrossRef]

23. Weiner, B. An attributional theory of achievement motivation and emotion. Psychol. Rev. 1985, 92, 548-573. [CrossRef]

24. Weiner, B. Human Motivation: Metaphors, Theory, and Research; Sage: Thousand Oaks, CA, USA, 1992.

25. Nelson, E.S.; Mathia, K. The relationships among college students' locus of control, learning styles, and self-prediction of grades. Educ. Res. Perspect. 1995, 22, 110-117.

26. Osborn, A.; Milbank, J. The Effects of Early Education: A Report from the Child Health and Education Study; Clarendon Press: Oxford, UK, 1987.

27. Choi, I.; Nisbett, R.E.; Norenzayan, A. Causal attribution across cultures: Variation and universality. Psychol. Bull. 1999, 125, 47-63. [CrossRef]

28. Chiu, L.H. A cross-cultural comparison of cognitive styles in Chinese and American children. Int. J. Psychol. 1972, 7, $235-242$. [CrossRef]

29. Cousins, S.D. Culture and self-perception in Japan and the United States. J. Pers. Soc. Psychol. 1989, 56, 124-131. [CrossRef]

30. Gobel, P.; Mori, S. Success and failure in the EFL classroom: Exploring students' attributional beliefs in language learning. In EUROSLA Yearbook 7; Roberts, L., Leah, A., Gürel, S., Tatar, S., Martı, L., Eds.; John Benjamins Publishing Company: Amsterdam, The Netherlands, 2007; pp. 149-169.

31. Mori, S.; Gobel, P.; Thepsiri, K.; Pojanapunya, P. Attributions for performance: A comparative study of Japanese and Thai university students. JALT J. 2010, 32, 5-28. [CrossRef]

32. Stevenson, H.; Stigler, J.W. The Learning Gap: Why Our Schools Are Failing and What We Can Learn from Japanese and Chinese Education; Summit Books: New York, NY, USA, 1992.

33. Thang, S.M.; Gobel, P.; Nor, N.F.M.; Suppiah, V.L. Students' attributions for success and failure in the learning of English as a second language: A comparison of undergraduates from six public universities in Malaysia. Pertanika J. Soc. Sci. Humanit. 2011, $19,459-474$

34. Bandura, A. Regulation of cognitive processes through perceived self-efficacy. Dev. Psychol. 1989, 25, 729-735. [CrossRef]

35. De Jong, J.; Moaddel, M. Trends in values among Saudi youth: Findings from values surveys. J. Hist. Child. Youth 2013, 6, 151-164. [CrossRef]

36. Haykel, B.; Hegghammer, T.; Lacroix, S. (Eds.) Saudi Arabia in Transition: Insights on Social, Political, Economic, and Religious Change; Cambridge University Press: Cambridge, UK, 2015.

37. Jiang, G.; Garris, C.P.; Aldamer, S. Individualism behind collectivism: A reflection from Saudi volunteers. VOLUNTAS Int. J. Volunt. Nonprofit Organ. 2018, 29, 144-159. [CrossRef]

38. Selvi, A.F.; Yazan, B. English as an international language pedagogy: A sustainable alternative for teaching English in the GCC region. In Challenges to Education in the GCC during the 21st Century; Mahboob, A., Elyas, T., Eds.; Gulf Research Center: Cambridge, UK, 2017; pp. 65-90.

39. Euchi, J.; Omri, A.; Al-Tit, A. The pillars of economic diversification in Saudi Arabia. World Rev. Sci. Technol. Sustain. Dev. 2018, 14, 330-343. [CrossRef]

40. Chen, G.; Gully, S.M.; Eden, D. Validation of a new general self-efficacy scale. Organ. Res. Method. 2001, 4, 62-83. [CrossRef]

41. McClure, J.; Meyer, L.H.; Garisch, J.; Fischer, R.; Weir, K.F.; Walkey, F.H. Students' attributions for their best and worst marks: Do they relate to achievement? Contemp. Educ. Psychol. 2011, 36, 71-81. [CrossRef]

42. Triandis, H.C.; Gelfand, M.J. Converging measurement of horizontal and vertical individualism and collectivism. J. Pers. Soc. Psychol. 1998, 74, 118-128. [CrossRef]

43. Chen, G.; Gully, S.M.; Whiteman, J.A.; Kilcullen, B.N. Examination of relationships among trait-like individual differences, state-like individual differences, and learning performance. J. Appl. Psychol. 2000, 85, 835-847. [CrossRef] [PubMed]

44. Bandura, A.; Schunk, D.H. Cultivating competence, self-efficacy, and intrinsic interest through proximal self-motivation. J. Pers. Soc. Psychol. 1981, 41, 586-598. [CrossRef]

45. Bandura, A. Perceived self-efficacy in cognitive development and functioning. Educ. Psychol. 1993, 28, 117-148. [CrossRef]

46. Berry, J.M.; West, R.L. Cognitive self-efficacy in relation to personal mastery and goal setting across the life span. Int. J. Behav. Dev. 1993, 16, 351-379. [CrossRef]

47. Eden, D. Self-fulfilling prophesy as a management tool. Acad. Manag. Rev. 1984, 9, 64-71. [CrossRef]

48. Eden, D. Pygmalion, goal-setting, and expectancy. Compatible ways to boost productivity. Acad. Manag. Rev. 1988, 13, 639-652. [CrossRef]

49. Lent, R.W.; Brown, S.D.; Larkin, K.C. Self-efficacy in the prediction of academic performance and perceived career options. J. Couns. Psychol. 1986, 33, 265-269. [CrossRef]

50. Usher, E.L.; Pajares, F. Sources of self-efficacy in school: Critical review of the literature and future directions. Rev. Educ. Res. 2008, 78, 751-796. [CrossRef]

51. Pilotti, M.A.; Alaoui, K.E.; Mulhem, H.A.; Salameh, M.H. A Close-up on a Predictive moment: Illusion of knowing or lack of confidence in self-assessment? J. Educ. 2021, 201, 256-261. [CrossRef] 
52. Pilotti, M.A.; El Alaoui, K.; Hamann, K.; Wilson, B.M. Causal attribution preferences and prospective self-assessment: The unknowns of the Middle Eastern learner. Int. J. Res. Educ. Sci. 2021, 7, 265-286. [CrossRef]

53. Lindley, L.D.; Borgen, F.H. Generalized self-efficacy, Holland theme self- efficacy, and academic performance. J. Career Assess. 2002, 10, 301-314. [CrossRef]

54. Vancouver, J.B.; Thompson, C.M.; Tischner, E.C.; Putka, D.J. Two studies examining the negative effect of self-efficacy on performance. J. Appl. Psychol. 2002, 87, 506-516. [CrossRef]

55. Zeegers, P. Student learning in higher education: A path analysis of academic achievement in science. High. Educ. Res. Dev. 2004, 23, 35-56. [CrossRef]

56. Hamann, K.; Pilotti, M.A.; Wilson, B.M. What lies beneath: The role of self-efficacy, causal attribution habits, and gender in accounting for the success of college students. Educ. Sci. 2021, 11, 333. [CrossRef]

57. Dresel, M.; Schober, B.; Ziegler, A. Nothing more than dimensions? Evidence for a surplus meaning of specific attributions. J. Educ. Res. 2005, 99, 31-45. [CrossRef]

58. Silver, W.S.; Mitchell, T.R.; Gist, M.E. Responses to successful and unsuccessful performance: The moderating effect of self-efficacy on the relationship between performance and attributions. Organ. Behav. Hum. Decis. Processes 1995, 62, 286-299. [CrossRef]

59. Hirschy, A.J.; Morris, J.R. Individual differences in attributional style: The relational influence of self-efficacy, self-esteem, and sex-role identity. Person. Indiv. Differ. 2002, 32, 183-196. [CrossRef]

60. Camgoz, S.M.; Tektas, O.O.; Metin, I. Academic attributional style, self-efficacy and gender: Across-cultural comparison. Soc. Behav. Personal. 2008, 36, 97-114. [CrossRef] 